\title{
Effects of Designed Educational Program about Reproductive Health on Nurses Knowledge
}

\author{
Nadia Abdalla Mohamed \& Nadia Hussein Ahmed. \\ Assistant Professor of Obstetrics and Gynecology Nursing Department, Faculty of Nursing, South Valley \\ University, Egypt. \\ Assistant Professor of Obstetrics and Gynecology Nursing Department, Faculty of Nursing, Assiut University, \\ Egypt.
}

\begin{abstract}
Reproductive health is an essential part of human health and development for women, particularly during their reproductive years. The aim of the study: To evaluate the effects of a designed educational program about reproductive health and on nurses' knowledge. Design: A pre- post- test, non- equivalent design was used. Setting: The study was conducted at 16 primary health care units and Maternal and child health units in Qena governorate. Sample purposive Convenient samples of 100 nurses working in the selected setting. Tools of data collection1Interview sheet to collect demographic data about nurses age ., Residence, and years of experience 2--: A structured test that was developed by the investigators to collect nurses knowledge about reproductive health pre and post test. The program: The nurses were divided into 4 groups ( 25 nurses in each). The training program was conducted over a period of 12 days; 3 days per group for 3 sessions per day for three months and post-test after six months covering all information and practices of the program. Results: the improves the level of knowledge of adequate level increased from $28 \%$ before the health education program to $98 \%$ and a significant difference in knowledge. Between Nurses working for 10 years or more than those working less than 10 years Conclusion: The education program markedly improves the level of knowledge of those with adequate level increased from $28 \%$ before the health education program to $98 \%$ after the program.
\end{abstract}

Keywords: Reproductive Health, Neonatal Health Care, Training, Nurses Knowledge \&PHC-MCH Units.

\section{Introduction}

Reproductive health has been a focus of health programs worldwide since the International Conference on Population and Development (ICPD) in 1994. However, in many countries, on- job training for nurses about sexual and reproductive health needs are often unrecognized or even neglected to this day. Globally, almost 16 million girls aged 15-19 years give birth each year, most prevalent in low- and middle-income countries located in sub-Saharan Africa (Christiansen, Gibbs, \& Chandra-Mouli 2013). A large number of these young women undergo unsafe abortions, where risks of dying from pregnancy-related causes are very high (WHO, 2012).

Primary health care centers in Egypt, provide outpatient health care and primary preventive activities for people in general and for mothers and children in particular. Medical care aims not only to improve health status but also to respond to patients' needs and wishes and to ensure their satisfaction with care (Awadalla et al., 2009).

The definition of reproductive health are the right of men and women to be informed of and to have access to safe, effective, affordable, acceptable methods of

fertility regulation of their choice and the right of access to appropriate health-care services that will enable women to go safely through pregnancy and childbirth and provide couples with the best chance of having a healthy infant (Madeni et al., 2010 (WHO, 2014).

Although the impact of family planning and reproductive health programs over the past five decades has been tremendous, numerous challenges remain (Cleland, 2006). An estimated 201 million women in developing countries have unmet needs for contraception due to lack of trained nurses and trained health personnel (Sonfield, 2006). A woman's lifetime risk of dying due to pregnancy and childbirth in developing countries is one in seventy-five (WHO, 2007). More than 500,000 women die annually from pregnancy-related complications and millions become ill from these complications. Altogether, 99\% of these deaths occur in the developing world, especially Africa, where the average risk of pregnancy-related death is 1 in 13, compared to 1 in 4085 in developed countries all due to lack of trained personnel. Also, about 7,400 adults and children worldwide become infected with HIV daily 
(UNAIDS, 2008) due to lack of health related information. In addition, $98 \%$ of neonatal deaths occur in developing countries, 42 neonates die per 1000 live births in Africa compared with at most 10 neonates per 1000 live births in developed countries also due to lack of trained health care personnel (Alan TNtita., et al, 2005).

According to Egypt's Ministry of Health and Population, maternal mortality rate (MMR) was 55 deaths for 100,000 live births in 2008, indicating a steady decline from 75 deaths for 100,000 live deaths in 2002 (CAPMAS, 2009). An estimated $40 \%$ of deaths in children under five occur in the first month of life, so improving newborn care is essential for further progress (Hogan et al, 2010). In 2012, the WHO reported that Egypt is one of 10 highperforming countries that is on the fast track in 2013 to achieve MDGs 4 to reduce child mortality and 5a to reduce maternal mortality (WHO 2012).

Ministry of health and population primary health care facilities provide maternal and child health services, communicable disease control, environmental health services and health education, amongst other services. There are approximately 5000 public primary care facilities and 1100 public hospitals in Egypt (WHO, 2010).

Egypt Service Provision Assessment Survey (ESPAS, 2004) found that the most effective way to prevent maternal deaths is to train nurses and skilled personnel who can recognize and treat or refer any complications that arise. Due to this training programs, maternal mortality rate (MMR) declined by over $56 \%$ between 1990 and 2000 (from 230 to 100 deaths per 100,000 live births) and then by $46 \%$ over the subsequent decade to 54 by 2010 according to national MDSR data due to implementation of effective training and educational programs for the health personnel. Training for reproductive health worker needs focus on improving both technical, interpersonal skills and counseling skills and reaching out under-served groups will be essential elements of such training (POPIN \& UNPF, 2014).

The major part of nurses' role in $\mathrm{MCH}$ centers is that of counselor and educator. To fulfill this role, nurses need updated information about contraceptive methods; they can increase the likelihood of a woman using contraception by providing contraceptive counseling that is directed to the woman's specific needs (McKinney, 2009). Health education is an essential role of today's nurse, it should begin early, before and during a woman's prenatal care and continues through her recovery from childbirth (McKinney, 2009), (Fraser \& Cooper, 2009).

One challenge to improve reproductive health outcomes is to effectively transfer evidence into practice because "knowledge-to-practice gap" continues to exist. Many health care workers lack the up-to-date evidence-based information they need to make informed decisions and provide effective care. Training and educating health care workers with the latest information, tools, resources and a venue for ongoing discussion will contribute to improving family planning and reproductive health outcomes (O'Brien \& Richey, 2014).

\section{Significance of the study}

Maternal health remains one of the Millennium Development Goal target for which progress has been most disappointing Improving newborn care is essential for prevention of needless and preventable death Through observation and follow-up of nurse's role in reproductive health, it was noticed that no recent on job training was done for the nurses regarding reproductive health and child health care which are necessary to improve quality of nursing care.

\section{Aims of the study}

- Assess knowledge of nurse's working at PHC and $\mathrm{MCH}$ units in Qena governorate about selected women reproductive health and neonatal health care issues.

- Evaluate the impact of Reproductive and neonatal health care educational program on nurses knowledge.

\section{Research Hypothesis}

Nurses who will attend the educational program will have higher knowledge score at the post-test than those of the pre-test.

\section{Subjects \& Methods}

\section{Study Design}

The research design used for this study was a prepost-test, non-equivalent, quasi-experimental design.

\section{Setting}

Qena governorate has $240 \mathrm{PHC}$ centers and $\mathrm{MCH}$ units. The study was conducted at $16 \mathrm{PHC}$ and $\mathrm{MCH}$ units who serve the approximately 16017 population. These $\mathrm{PHC}$ and $\mathrm{MCH}$ were selected because they represent $43 \%$ of the total number of $\mathrm{PHC}, \mathrm{MCH}$ in Qena governorate and serve the most highly populated areas.

\section{Subjects}

The number of nurses in each $\mathrm{PHC} / \mathrm{MCH}$ units ranges between 6-8 nurses. A convenient sample of all available nurses at the time of data collection was used. The number of nurses who agreed to participate in the study reached110 nurses Almost six- 7 nurses was recruited from each setting. Ten nurses were used for the pilot study and excluded from the study 
subjects, and the 100 nurses were considered the study subjects. The nurses were divided into four groups 25 nurses in each group.

Duration of the study: The study started from November 2013 - February 2014.

Tools used for data collection consisted of:

- An Interview sheet that was designed by the investigator to collect occupational data as, the length of experience.

- A structured test was developed by the investigator to assess nurses' knowledge about reproductive health and (antenatal, natal and postnatal care.) The test was used as a pre-test to assess baseline knowledge of nurses before the educational program, then the educational program for three months, after that used as post-test after six months to evaluate the success rate of the educational program. The test included 19 multiple choice questions, it covered 6 topics derived from an assessment of the nurses knowledge.

Levels of knowledge were coded according to the following

Adequate knowledge, if the nurse answered correctly $75 \%$ or more of the questions;

Satisfactory knowledge, if the nurse answered correctly between $50-74 \%$ of the questions;

Inadequate knowledge, if the nurse answered correctly less than $50 \%$ of the questions.

Validity and reliability

The reliability of the tool was measured using test retest with 10 nurses who were given the structured test two times 15 days apart. The results of the two answers were compared. The reliability was $\mathrm{r}=89 \%$. These nurses were excluded from the study.

The validity was measured by 3 professors in the field of maternal and child health. Their comments and suggestions were considered and the necessary modifications were done.

\section{Pilot study}

The researcher implemented the structured test for a group of 10 nurses to assess the applicability, and feasibility of the test and the time needed for data collection. The researchers asked the nurses in the pilot study to evaluate the content of the questionnaire and if they have any other suggestions or needs to be covered. Their responses and suggestions were taken into consideration and the needed modifications were done.

\section{Ethical considerations}

Protection of subjects from harm or discomfort was achieved since there are no invasive procedures involved. In addition, nurses were asked not to write their names for confidentiality of information and they were assured that the test results will be used only for the study and will not be used for any other reason.

\section{Procedure}

The program was implemented in the following phases

- The preparatory phaseThis phase was based on the observation and follow-up of nurses' role in PHC and $\mathrm{MCH}$ units (the 16 units) in Qena governorate. The observation revealed a need to improve the nursing role and that no recent training was done for nurses regarding reproductive health and child health care to improve the quality of nursing care Also, the extensive literature review for preparing the prepost- test was done. It contained multiple choice questions about maternal care, care for high-risk pregnancy, care of the newborn, family planning, counseling on reproductive health and family planning record. This phase took 3 months. Then the researchers analyzed the pre-test.

- Tailoring the program contents: The program contents were developed based on the analysis of the pre-test and current literature and modified according to the revealed nurse's needs during the pilot study.

- Implementation phase: Different teaching methods were used, it includes lectures, discussions, brainstorming, various visuals and instructional media were used in the form of posters and handouts. The sample was divided into four groups. The educational program was conducted for each group over a period of 6 days; 6 hours every day to cover all information and practices of the program content.

\section{Evaluation phase}

After finalizing the educational program for each group, the post-test was administered, analyzed and compared with the results of the pretest to evaluate the success of the educational program to achieve the aim of the study and the research hypothesis.

\section{Statistical Analysis}

The data were coded and verified prior to data entry. The Statistical Package of SPSS version 16 for windows was used for data entry and analysis. Descriptive Statistics were calculated. $\mathrm{Chi}^{2}$ test was used in dealing with qualitative data. To compare two proportions $\mathrm{Z}$ test was used. A significant $\mathrm{P}$-value was considered when $\mathrm{P}$ was less than 0.05 and or 0.001 . 


\section{Results}

Table (1): Socio-demographic and educational characteristics of the nurses.

\begin{tabular}{|c|c|c|}
\hline & Frequency & Percent \\
\hline \multicolumn{3}{|l|}{ Age (years) } \\
\hline$<20$ & 20 & $20 \%$ \\
\hline $20-30$ & 15 & $15 \%$ \\
\hline $31-40$ & 35 & $35 \%$ \\
\hline $40+$ & 30 & $30 \%$ \\
\hline \multicolumn{3}{|l|}{ Range } \\
\hline \multicolumn{3}{|l|}{ mean $-25 \& \mathrm{SD} \pm 7.91$} \\
\hline \multicolumn{3}{|l|}{ Residence } \\
\hline Urban & 60 & $60 \%$ \\
\hline Rural & 40 & $40 \%$ \\
\hline \multicolumn{3}{|l|}{ Nursing education level } \\
\hline Diploma & 88 & $88 \%$ \\
\hline Technical institute & 2 & $2 \%$ \\
\hline
\end{tabular}

Table (2): Percentage distribution of level of the studied nurses' knowledge and years of experience.

\begin{tabular}{|c|c|c|c|c|c|c|c|c|}
\hline \multirow{3}{*}{ Years of experience } & \multicolumn{6}{|c|}{ Level of Knowledge } & \multirow{2}{*}{\multicolumn{2}{|c|}{ Total }} \\
\hline & \multicolumn{2}{|c|}{ inadequate } & \multicolumn{2}{|c|}{ satisfactory } & \multicolumn{2}{|c|}{ Adequate } & & \\
\hline & No. & $\%$ & No. & $\%$ & No. & $\%$ & No. & $\%$ \\
\hline$<10$ years & 18 & 18.0 & 16 & 16.0 & 8 & 8.0 & 42 & 100.0 \\
\hline 10 years or more & 4 & 22.0 & 34 & 34.0 & 20 & 20.0 & 58 & 100.0 \\
\hline Total & 22 & 22.0 & 50 & 50.0 & 28 & 28.0 & 100 & 100.0 \\
\hline
\end{tabular}

Table (3): Percentage distribution of knowledge change regarding reproductive health counseling and documentation among the studied nurses pre- and post- education program.

\begin{tabular}{|l|c|c|c|c|c|}
\hline $\begin{array}{c}\text { Reproductive health counseling and } \\
\text { documentation }\end{array}$ & $\begin{array}{c}\text { \% of Pre- ed. } \\
\text { Program }\end{array}$ & $\begin{array}{c}\text { \% of Post- } \\
\text { ed program }\end{array}$ & $\begin{array}{c}\text { \% of } \\
\text { Change }\end{array}$ & $\begin{array}{c}\text { Chi- } \\
\text { square }\end{array}$ & P value \\
\hline $\begin{array}{l}\text { The uses of medical visual aids by the } \\
\text { nurse are: }\end{array}$ & 42.0 & 98.0 & 56.0 & 74.5 & 0.007 \\
\hline $\begin{array}{l}\text { reproductive health counseling and } \\
\text { neonatal health care }\end{array}$ & 26.0 & 78.0 & 61.0 & 54.2 & 0.001 \\
\hline Pre- marital counseling & 58.0 & 68.0 & 10.0 & 2.15 & 0.2 \\
\hline $\begin{array}{l}\text { The purpose from prenatal follow up } \\
\text { documentation }\end{array}$ & 46.0 & 66.0 & 20.0 & 15.3 & 0.1 \\
\hline $\begin{array}{l}\text { Neonatal age registration in follow up } \\
\text { records }\end{array}$ & 22.0 & 54.0 & 32.0 & 2.54 & 0.04 \\
\hline Keeping client card & 18.0 & 94.0 & 76.0 & 117.2 & 0.0001 \\
\hline
\end{tabular}


Table (4): Percentage of change of nurse's knowledge regarding antenatal, natal and post-natal care pre- and post- training program among those working at Qena PHC and MCH units, 2013 - 2014.

\begin{tabular}{|l|c|c|}
\hline \multicolumn{1}{|c|}{ Antenatal, natal and postnatal care } & Change \% & P-value \\
\hline The nurse's role in pregnancy and delivery & 32.0 & 0.04 \\
\hline The minimum number of prenatal visits & 48.0 & 0.01 \\
\hline Immunity of the first tetanus dose during pregnancy & 32.0 & 0.04 \\
\hline Causes of early bleeding during pregnancy & 44.0 & 0.02 \\
\hline Maternal mortality means & 60.0 & 0.001 \\
\hline The nurse should do uterine massage during first two hours of labor at a rate of & 44.0 & 0.02 \\
\hline Types considered hormonal contraceptive methods & 12.0 & 0.2 \\
\hline The action of Pills to prevent pregnancy & 52.0 & 0.009 \\
\hline Criteria to use breastfeeding as a contraceptive method & 8.0 & 0.2 \\
\hline
\end{tabular}

Table (5): Percentage distribution of changes in the studied nurse's knowledge in items of neonatal care at pre- and post- education program.

\begin{tabular}{|l|c|c|c|c|c|}
\hline \multicolumn{1}{|c|}{ Neonatal care } & $\begin{array}{c}\text { \% of Pre- ed. } \\
\text { Program }\end{array}$ & $\begin{array}{c}\text { \% of Post- } \\
\text { ed program }\end{array}$ & $\begin{array}{c}\text { \% of } \\
\text { Change }\end{array}$ & $\begin{array}{c}\text { Chi- } \\
\text { square }\end{array}$ & P value \\
\hline $\begin{array}{l}\text { The first nursing action must be } \\
\text { done for neonatal resuscitation }\end{array}$ & 36 & 76 & 40.0 & 32.5 & 0.03 \\
\hline $\begin{array}{l}\text { The newborn position the nurse put } \\
\text { to measure his length }\end{array}$ & 68 & 98. & 16.0 & 31.9 & 0.1 \\
\hline $\begin{array}{l}\text { What the nurse should do after } \\
\text { taking blood sample from heel } \\
\text { prick }\end{array}$ & 56 & 98. & 42.0 & 3.9 & 0.03 \\
\hline $\begin{array}{l}\text { Acute side effects of circumcision } \\
\text { that can lead to death }\end{array}$ & 76 & 94. & 26.0 & 12.7 & 0.08 \\
\hline
\end{tabular}

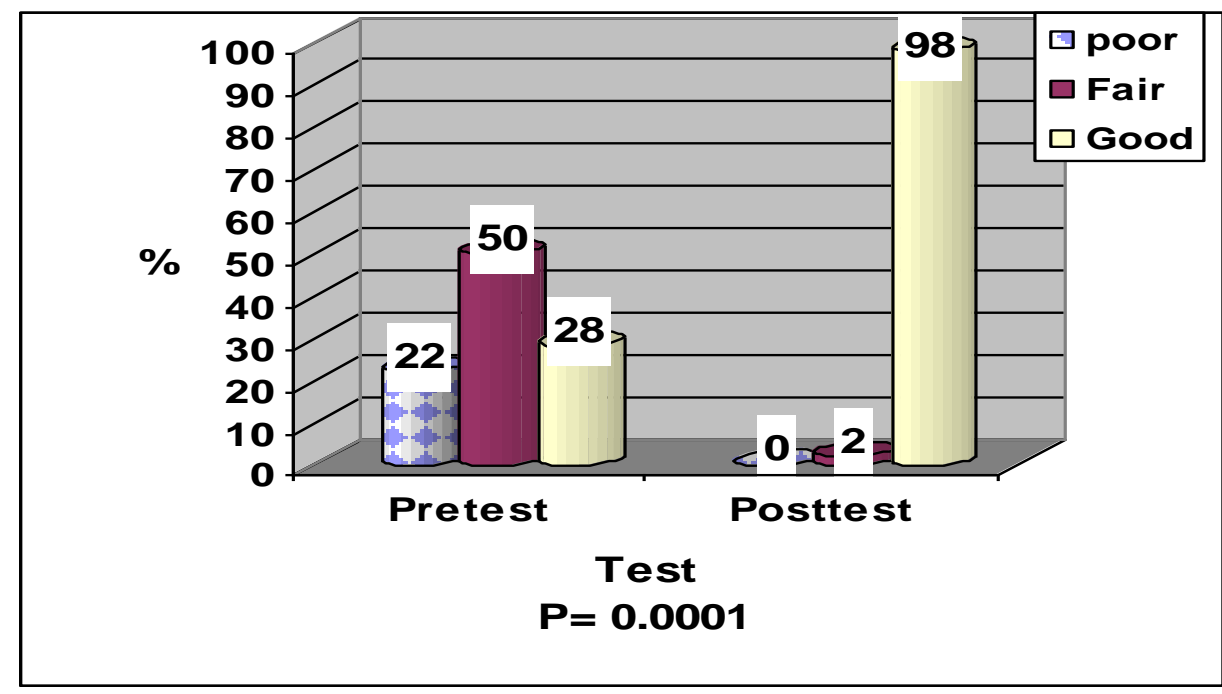

Figure (1): Levels of Knowledge of the studied nurses in the pre- post- education program Chi-square $=105.2 \quad p<0.001 * *$ 
Table (1): Socio-demographic data Table(1). The third of the sample age range between 31-40 years $(35 \%)$ also more than 40 years $(30 \%)$ more than half from urban and the majority are Diploma(80\%) secondary education

Table (2): Showed that 22\%, 50\% and $28 \%$ of the studied nurses had inadequate, satisfactory and adequate knowledge respectively. The percentage of nurses with adequate knowledge were higher (20\%) among those working for ten years or more than those working for less than ten years $(8 \%)$ and this difference was statistically significant $(\mathrm{P}=0.01)$.

Knowledge change regarding reproductive health at pre - and post- implementation of the educational program was presented in

Table (3): In this regard, the most statistically significant change was in the knowledge of nurses about record keeping ( $\mathrm{p}<0.0001$ ), followed by reproductive health counseling $(\mathrm{p}<0.001)$, then the use of visual aids where $p$ <0.007). The least changed item was the content of pre-marital counseling as $58 \%$ in pre-test knew that preventing consanguineous marriage is not one of its contents compared to $68 \%$ at the post-test $(\mathrm{p}=0.2)$.

Knowledge regarding antenatal, natal and post-natal care pre- and post-the educational program was presented in

Table (4): The table revealed that knowledge of nurses had changed after the educational program. However, nurses' knowledge about the meaning of maternal mortality and action of pills to prevent pregnancy were the only statistically significantly changed items at the post-education program ( $\mathrm{p}<$ $0.001, \mathrm{p}<0.009$ respectively). The least changed item was the criteria to use breastfeeding as a contraceptive method ( $\mathrm{p}<0.2)$.

Table (5): showed that $76 \%, 98 \%, 98 \%$ and $94 \%$ of nurses in the post-test had correct answers related to neonatal care including the first nursing action that must be done for neonatal resuscitation, the position used to measure length of the newborn, nursing action after taking blood sample from the heel and acute side effects of circumcision that can lead to death compared to $36 \%, 82 \%, 56 \%$ and $68 \%$ in the pre-test respectively.

Figure (1): Regarding level of nurse's knowledge in general, the percentage of those with good level was improved markedly from $28 \%$ in the pretest to $98 \%$ in the posttest and the difference was statistically significant $(P<0.0001)$ as shown in figure (1) Chisquare $=105.2$

\section{Discussion}

Once a woman becomes pregnant, interventions may be too late to address preexisting health complications, or identified obstetrical risks from past pregnancies, such as gestational diabetes. Nursing care for Women's Health, Obstetric and Neonatal Nurses is a comprehensive approach to providing targeted care at all stages of a woman's reproductive life in preconception, antenatal, natal postnatal and postpartum infant care. Access to reliable evidence-based information is crucial in developing countries to decrease maternal and neonatal mortalities (Alan et al., 2005). The Global Alliance for Nursing and Midwifery (GANM) Established in 2005 by WHO and many nursing and midwifery collaborating centers, has brought increased attention to the vital role of nursing and midwifery in the global health agenda. Now it connects nearly 2,000 members from 140 countries, providing opportunities to exchange knowledge, fill information gaps, share experiences and good practices capabilities (Johns Hopkins University School of Nursing, 2009).

The findings of the current study revealed that the most statistically significant change was in nurses' knowledge regarding reproductive health counseling and documentation was about record keeping, followed by reproductive health counseling, then the use of visual aids. This improvement in the studied nurses' knowledge will lead to more accurate record keeping for effective follow-up activities and efficient use of the visual aids materials available in the MCH. This is constant with The Egypt Ministry of Health \& Population (MOHP), 2003) reported that visual aids materials are available in $87 \%$ of health facilities, $79 \%$ had teaching aids about specific types of family planning and $84 \%$ had information pamphlets for clients to take home. Visual aids related to sexually transmitted diseases (STIs) are available in the family planning service area in $17 \%$ of the facilities and information pamphlets on STIs that clients can take home are available in $32 \%$ of facilities the less availability of these services lead to less information of the nurses.

Concerning the effectiveness of the education programs in improving nurses' knowledge, (Nabhana \& Tawfik, (2007) reported that poor diagnosis and management by providers is aggravated by, lack of knowledge, absence of communication between primary- and next-level care providers and failure to keep records. This finding was in the same line with that of the MOHP, together with UNFPA, UNICEF, and USAID, who undertaken initiatives to increase the equitable distribution and training of the health workforce. The MOHP implemented an integrated set of interventions as a part of the Healthy Mother/Healthy Child Project (1993-2009) to improve the quality of obstetric and emergency care: for instance, competency-based training was 
conducted to improve skills of health personnel, and to train nurses in midwifery skills. The MOHP also had an ongoing training program for nurses to become skilled midwives and has significantly improved the training and professionalism of its secondary-level nurses.

Likewise, these findings are supported by the results of a project conducted in Armenia (2010), where eighty nurses working in rural communities were trained to offer comprehensive individual counseling and group health education classes to women who are making reproductive health decisions and choices about their neonatal health. They were using "balanced counseling," a technique developed by the Population Council. Balanced counseling employs job aids such as brochures and flips charts that were developed by the Intra-Health International.

(Armenian Nurses Trained to Offer In-Depth Reproductive Health Counseling, (2014).

Reported that the means that improvement in nurses' knowledge through in- job education is an effective strategy because it may lead to improving a woman's health before and between pregnancies which are important for the outcomes of the woman and her baby.

In the current study, the findings showed a statistically significant improvement in nurses knowledge related to antenatal, natal and post-natal care at the post-test than that of the pre-test. The knowledge of nurses about maternal mortality was the most changed item in the post-intervention. While in the (Madeni et al., 2011), the largest increase in providers' knowledge was observed for postnatal care (45\% increases in the correct answers). This difference could be due to cultural and need variation between Egypt and Romania. In addition( Zaruhi et al., 2007) conducted a baseline assessment of health care facilities to collect data on the performance of health care providers in delivering antenatal care and postpartum/infant care, they found that health care providers were not performing to the level of internationally-accepted standards $(85 \%$ of the tasks expected). In assessing performance, nurses only performed $29 \%$ of the basic ante-natal care tasks, midwives, $43 \%$ and physicians $58 \%$. Nurses performed $35 \%$ of the tasks needed to provide basic Postpartum/Infant care. Counseling on ante-natal care and postpartum is the weakest among both nurses and physicians and basic clinical skills are also low: $33 \%$ for ANC and 24\% for PP/IC.

As regard to neonatal care, the current study revealed that knowledge of nurses about the first nursing action that must be done for neonatal resuscitation, a newborn position to measure length, what should the nurse do after talking blood sample and acute side effects of circumcision that can lead to death were improved at the post intervention. These results were in accordance with the results of the study done by (McClure et al, 2007) they evaluated the effectiveness of the World Health Organization (WHO) Essential Newborn Care (ENC) course in improving knowledge and skills of nurse midwives in low-risk delivery clinics in a developing country. They found that both the knowledge and skills of the nurse midwives improved significantly following the course (from $65 \%$ correct pre-training to $84 \%$ correct post-training and from $65 \%$ to $77 \%$ correct on the performance and written evaluations, respectively). The current study results is also congruent with the findings of (Carlo, et al., 2009), who evaluated the effectiveness of the American Academy of Pediatrics Neonatal Resuscitation Program (NRP) in improving knowledge, skills, and self-efficacy of nurse midwives in low-risk delivery clinics in a developing country, it revealed that after training nurses knowledge improved markedly.

Regarding the level of knowledge in general, all pretest results were relatively low and the percentage of those with good level was improved in the post-test and the difference was significant $(\mathrm{P}<0.0001)$. This finding is in agreement with the findings of the( Madeni et al., 2011) which illustrated that all pretraining test results were relatively low and providers answered about half of all questions correctly. Also, in Uganda, the Uganda government worked with "Intra Health's Uganda Capacity Program" which is funded by USAID/Uganda to develop and implement upgrading of existing nurses in the skills and knowledge through a six-month in-service training course in family planning and safe motherhood (Karen, 2013). This project was given since many of the nurses in Uganda were by default "doing it all," offering an area of facility-based and community services, they weren't fully trained to provide because there was no one else to deliver care. It's demoralizing when they are put in a position to provide the care they simply aren't prepared to give it.

To achieve Millennium Development goals in maternal and reproductive health in countries struggling with high maternal and neonatal morbidity and mortality, all that is needed is just trained nurses; and health care providers. Upgrading nurse's skills and knowledge not only promises to save the lives of more mothers and neonates, but it will also offer these nurses career advancement that will benefit them as well as their families.

\section{Conclusions}

There was a general lack of knowledge regarding various aspects of reproductive health and child 
health care among nurses. Half of the primary health care and maternal and child health units nurses working in Qena governorate have an adequate level of knowledge regarding reproductive health and neonatal health care while $22 \%$ of them have a low level of knowledge. The education program markedly improves the level of knowledge as the percentage of those with adequate level increased from $28 \%$ before the health education program to $98 \%$ after the program.

\section{Recommendations}

There is an urgent need to design through work educational programs to improve nurse's knowledge about reproductive health and neonatal health care. More researches are needed to identify nurses knowledge regarding the most evident based practices to enhance promote health care.

\section{References}

1. Alan T, Beatrice S., Kim W., Asha K., \& Sylvestre D., (2005): Evidence-based reproductive health care in Cameroon: a population-based study of awareness, use and barriers. Bull. World Health Organ., vol.83 no.12 General Dec. 2005.

2. Armenian Nurses Trained to Offer In-Depth Reproductive Health Counseling during (2010): Retrieved on 2014 from http://www.intrahealth.org/page/armeniannurses-trained-to-offer-in-depth-reproductivehealth-counseling.

3. Awadalla H., Kamel E., Mahfouz E., \& Refaat T., (2009): Evaluation of maternal and child health services in El-Minia City, Egypt. Journal of Public Health, Volume 17, Number 5, 321-329, DOI: 10.1007/s10389-009-0255-8.

4. Bechalt M., Ellott M., Martion S., Kanouse D., Corona R., (2010): Timing and child communication about sexual and reproductive health in rural Tanzania Implication for young people,s sexual health intervention,7.6

5. Carlo A., Wright L., Chomba E., McClure EM, Carlo ME, Bann CM, Collins M, and Harris H., (2009): Educational impact of the neonatal resuscitation program in low-risk delivery centers in a developing country. J. Pediatr. Apr;154 (4):504-508.

6. Central Agency for Public Mobilization \& Statistics (CAPMAS), (2009): Annual Report, Egypt: CAPMAS Publications. FIND A MORE RECENT STATISTICS

7. Cleland, J., Bernstein, S., Ezeh, A., Faundes, A., Glasier, A., \& Innis, J., (2006): Family planning: The unfinished agenda. Lancet, 368(9549), 1810-1827.

8. Egypt service provision assessment survey (2004): Ministry of Health and Population [EGYPT] published Apr. 2005.

9. Fraser D., \& Cooper M., (2009): Myles textbook for midwives, Antenatal care, $5^{\text {th }}$. Edition, Churchill Livingstone, London.

10. Hogan M., Foreman K., Naghavi M, Ahn S., Wang M., Makela S., (2010): Maternal mortality for 181 countries, 1980-2008: a systematic analysis of progress towards Millennium Development Goal 5. Lancet 375:1609-23.

11. Johns Hopkins University School of Nursing, (2009): Web-wise nurses harness new media for global health. News Release. Aug. 10, 2009. Retrieved from: http://www.son.jhmi.edu/newsevents/news/news. aspx?ID=431

12. Karen B., (2013): Nurses Can Close the Millennium Development Goals Gaps in Maternal and Reproductive Health, http://www.intrahealth.org/blog

13. Madeni, F., Horiuchi S., Jitsuszaki, M., (2011): Evaluation of A reproductive health awareness Program for adolescents in Tanzania, A quasi-experimental pretest'posttest Research Reproductive Health 8-11

14. McClure E., Carlo W., Wright L., Chomba E., Uxa F., Lincetto O., Bann C., (2007): Evaluation of the educational impact of the WHO Essential Newborn Care course in Zambia. Acta Paediatr. 2007 Aug; 96(8):1135-8.

15. Mckinney E., Janes R., Murray S., \& Ashwill W., (2009): Maternal and Child Health, Management of Fertility and Infertility, $3^{\text {rd }}$. edition . Saunders Elsevier, Canada, P.N 25, 185.

16. Ministry of Health \& Population (MOHP) [Egypt], (2003): El-Zanaty Associates, and ORC Macro. Egypt Service Provision Assessment Survey 2002. Calverton, Maryland

17. Nabhana A., \& Ahmed T., (2007): Understanding and attitudes towards patient

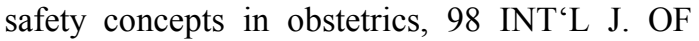
GYNECOLOGY AND OBSTETRICS 212215.18. Nurses Must Provide Reproductive Health Counseling Before Pregnancy (2011). Monday, February 14, at http://news.nurse.com/article/20110214/NATIO NAL02/102140038/1/frontpage\#.UvX5VaDnZjo

18. O'Brien M., \& Richey C., (2014): Knowledge Networking for Family Planning: The Potential for Virtual Communities of Practice to Move Forward the Global Reproductive Health 
Agenda.

Knowledge Management \& E-Learning: An International Journal, Vol.2, No.2. P: 109- 121.

19. Sonfield, A., (2006): Working to eliminate the world's unmet need for contraception. Guttmacher Policy Review 9, 1 at http://www.guttmacher.org/pubs/gpr/09/1/gpr09 0110.html

20. United Nations, (2002): Program of action of the International Conference on Population and Development, paragraph 7.2, at: www.iisd.ca/linkages/Cairo/program/p07002.ht $\mathrm{ml}$ old reference

21. UNAIDS, (2008): United Nation Report on the global AIDS epidemic. Retrieved from http://www.unaids.org/en/KnowledgeCentre/HI VData/GlobalReport/2008/2008_Global_report. asp

22. United Nations Population Information Network (UNPIN), UN Population Division, Department of Economic and Social Affairs with support from the UN Population Fund (2014):

http://www.un.org/popin/unfpa/taskforce/guide/i atfreph.gdl.html

23. World Health Organization (WHO),(2007): Maternal mortality in 2005: Estimates developed by WHO, UNICEF, UNFPA and the World Bank. Retrieved from: http://www.who.int/whosis/mme_2005.pdf

24. WHO, (2008): World Health Organization Reproductive Health Strategy. Retrieved 200807-24 at http://www.who.int/reproductivehealth/strategy.htm

25. WHO, (2014): Reproductive health during conflict and displacement. Dr. Tomris Türmen, CHAPTER 2: Reproductive health needs that arise during conflict and displacement ...... among women of reproductive age (15-44 years) ... always reflect earlier reproductive life events. Retrieved Feb, 2014 from: whqlibdoc.who.int/hq/2001/WHO_RHR_00.13.p df

26. Zaruhi Mkrtchyan Z., Sacci I., \& Vardanyan M., (2007): Reproductive, maternal and child services in health network, Baseline assessment of reproductive, maternal and child services in project NOVA supported networks.

27. WFUNA. Egypt: Post (2015): National Consultations. (United Nations, Geneva, 2013)Human DevelopmentIndicators. http://hdrstats.undp.org/en/countries/profiles/EG Y.html

28. Who (2014): Safe Abortion: Technical and Policy Guidance for Health Systems. Second edition. Geneva: World Health Organization-
Department of Reproductive Health and Research. 